\title{
Pregnancy in PCOS Women and their History of Diabetes
}

\section{Mette Viftrup-Lund, Melina Gade and Finn F Lauszus}

Department of Gynecology and Obstetrics, Herning Hospital, Denmark

*Corresponding author: Finn Friis Lauszus, Senior Consultant, Department of Gynecology and Obstetrics, Herning Hospital, GI. Landevej 61, DK-7400 Herning, Denmark, Tel: 45784236 14; fax: 45784346 36; E-mail: finlau@rm.dk

Received date: August 28, 2014; Accepted date: September 09, 2014; Published date: September 14, 2014

Copyright: (c) 2014 Viftrup-Lund $\mathrm{M}$ et al. This is an open-access article distributed under the terms of the Creative Co mmons Attribution License, which permits unrestricted use, distribution, and reproduction in any medium, provided the original author and source are credited.

\begin{abstract}
Objective: Evaluation of the incidence of gestational diabetes in PCOS women treated with metformin before and during early pregnancy and to ascertain their family history of diabetes.

Design: Follow-up on all women with PCOS and infertility who received treatment with metformin prior to pregnancy (=index pregnancy) during 10 years. Data on diabetes was retrieved by questionnaire and hospital charts. Main outcome measures: Incidence of gestational diabetes, pregnancy outcome, and fetal size

Results: In $18 \%$ of the women GDM was diagnosed at some stage. The clinical and obstetrical outcome of the women showed no association with family history of diabetes or GDM. No neonatal anthropometric feature was different with respect to family history of diabetes or GDM and no fetal malformations were found
\end{abstract}

Conclusion: GDM and family history of diabetes seem not to be associated with unfavourable pregnancy outcome in PCOS women.

Keywords: Metformin; Pregnancy; Pregnancy loss; Malformation; Polycystic ovarian syndrome

\section{Abbreviations: \\ DHAS: Dihydroepiandrosterone sulphate; GDM: Gestational diabetes; PCOS: Polycystic ovary syndrome; SHBG: Sexual hormone binding globulin; FAI: Calculated free androgen index; IUI: Intrauterin insemination; IVF: In-vitro fertilization}

\section{Introduction}

Polycystic ovarian syndrome (PCOS) is the most common endocrine disorder in women of fertile age with an estimated prevalence of up to $5-10 \%$. Hyperandrogenism and insulin resistance are cornerstones of PCOS, even though not mandatory according to the consensus criteria [1]. Metformin improves metabolic, endocrine, and ovulatory parameters, probably improving fertility in women with PCOS. Pregnancy and PCOS are variably associated with higher risk of developing gestational diabetes (GDM), pregnancy-induced hypertension, preeclampsia, and preterm birth; however, the contribution of obesity to the prevalence of obstetrical morbidity is unresolved [2]. Several retrospective and non-randomized studies have reported beneficial effects of metformin on pregnancy complications, but this is not supported by a randomized, double-blinded controlled trial [3].

In this study we sought to evaluate the incidence of gestational diabetes, pregnancy outcome, and fetal size in women treated with metformin before and during early pregnancy and to ascertain their family history of diabetes.

\section{Materials and Methods}

We examined the records of all women with PCOS and infertility who received treatment with metformin prior to pregnancy (=index pregnancy). They were referred to the Department of Gynecology at Herning and Holstebro Hospital, Denmark, during from 1999 to 2010. We defined our PCOS inclusion criteria as presence of amenorrhea, oligomenorrhea or irregular menstruation with anovulation and concomitant elevated plasma-testosterone $(>1.8 \mathrm{nmol} / \mathrm{l})$. Oligomenorrhea was defined as cycle duration between 35 days and 6 months and amenorrhea as the absence of menstruation for more than 6 months. Exclusion criteria were type 1 and 2 diabetes mellitus. A total of 117 women fulfilled our criteria. The study was approved by the Danish Data Protection Agency (no. 2013-41-1998) and conducted in accordance with the Helsinki Declaration and the guidelines for Good Clinical Practice. Questionnaires do not need approval by the Danish Ethical Committee system according to its regulatory law.

Through our records we obtained information about age, BMI, former pregnancies, former infertility treatment, and menstrual cycle pattern as well as information about conception method and consumption of medicine, tobacco, and alcohol. Our records also included plasma levels of $\mathrm{LH}, \mathrm{FSH}$, testosterone, dihydroepiandrosterone sulphate (DHAS), sexual hormone binding globulin (SHBG), thyroid stimulating hormone, prolactin (measured in early follicular phase or at random in amenorrhic women), progesterone (measured one week before expected menstruation or at random in amenorrhic women), and a calculated free androgen index $(\mathrm{FAI}=$ testosterone/SHBG $)$. A physical examination was performed at first visit including a gynecological examination and vaginal ultrasound.

We supplemented our data with a questionnaire mailed to the women; we ascertained hereby information about the first pregnancy 
Page 2 of 5

outcome associated with metformin use, neonatal weight and height, neonatal malformations, gestational age at birth, pregnancy complications like gestational diabetes and preeclampsia, smoking and alcohol use, medication taken during pregnancy, family history of diabetes, cardiovascular and endocrine disease, cholesterol and genetic disorders. These data in the responding women were supplemented and compared with the medical records of mother and infant. The non-responding women's data charts were scrutinized for relevant, historical obstetrical data and compared with the responders where appropriate.

The women received metformin treatment at standard dosage 850 mg twice a day. The fertility treatment consisted of first line clomiphene for six months followed by three months of intrauterine insemination (IUI). If no pregnancy was achieved the couple was referred to in-vitro fertilization (IVF) treatment. Heterologue insemination was discussed if oligospermia was found in two sperm samples. If sterility (tubal occlusion or azoospermia) was present further treatment was at the IVF clinic. If the couple had no child they were eligible for free IVF treatment. The women were told to continue with metformin treatment for no longer than the 7 th gestational week where the first ultrasound could verify a viable fetus.

For statistical calculations of proportions the $\chi^{2}$-test with Yates' correction for discontinuity was applied. If the expected number was less than five, Fisher's Exact test was used. For continuous variables Student's t-test, Mann-Whitney's U-test, and Wilcoxon's Signed Rank test was used when appropriate. ANOVA was performed between group variables. Post-hoc test with Newman-Keul's test was performed between group pairs. The level of significance was 0.05. IBM SPSS Statistics 20 was used as the statistical software.

\section{Results}

A total of 117 PCOS women with pregnancies and periconceptional metformin were included in the study and questionnaires were mailed to them; hereof 76 (65\%) responded. The initial blood sample was drawn on day 3 or 4 in cycle; if she had oligo-/amenorrhea testing was performed on the same day (Table 1).

\begin{tabular}{|c|c|c|c|c|}
\hline & \multicolumn{2}{|c|}{ The 76 included women } & \multicolumn{2}{|c|}{ In 41 non-responding women } \\
\hline & $\begin{array}{l}\text { Before } \\
\text { treatment }\end{array}$ & $\begin{array}{l}\begin{array}{l}3-6 \text { months after treatment } \\
(n=59)\end{array}\end{array}$ & Before metformin treatment & $\begin{array}{l}\text { 3-6 months after treatment } \\
(\mathrm{n}=27)\end{array}$ \\
\hline Age at treatment (yrs) & $29 \pm 4$ & & $29 \pm 4$ & \\
\hline Weight kg & $88 \pm 21(59,139)$ & & $83 \pm 26(47,150)$ & \\
\hline $\mathrm{BMI} \mathbf{k g} / \mathbf{m}^{2}$ & $31 \pm 7(18,47)$ & & $29 \pm 8(17,51)$ & \\
\hline Testosterone (nmol/l) & $2.93 \pm 1.0(1.91,6.74) \S$ & $1.74 \pm 0.7(0.52,3.74)^{* *}$ & $2.60 \pm 0.5(1.81,4.32)$ & $1.63 \pm 0.6(0.57,3.32)$ \\
\hline Testosterone > 2.4 (no.(\%)) & $47(62)$ & $7(12)$ ** & $25(61)$ & 0 ** \\
\hline DHAS(nmol/l) & $5934 \pm 3084(837,15000)$ & $4921 \pm 2357(1680,11000)$ & $5256 \pm 2151(1956,12131)$ & $5251 \pm 2040(2290,9828)$ ** \\
\hline SHBG(nmol/I) & $44 \pm 25(9,132)$ & $49 \pm 27(13,137)^{*}$ & $45 \pm 27(18,134)$ & $56 \pm 46(16,229)$ ** \\
\hline FAI (\%) & $9.0 \pm 6.3(2.2,26.9)$ & $4.7 \pm 3.2(0.9,17.0)^{\star *}$ & $7.4 \pm 4.3(1.6,24)$ & $5.0 \pm 4.1(1.1,21)^{* *}$ \\
\hline $\begin{array}{l}\text { FAl above } 97.5 \text { percentile (FAl=7\%) } \\
\text { (no. }(\%))\end{array}$ & $35(46)$ & $9(16)$ ** & $18(44)$ & $4(15)^{* *}$ \\
\hline $\mathrm{FSH}(\mathrm{IE} / \mathrm{I})$ & $5.6 \pm 6.4(0.4,55.9)$ & $4.7 \pm 1.8(0.8,8.6)$ & $4.7 \pm 1.8(1.2,8)$ & $4.9 \pm 1.8(1.2,8.9)$ \\
\hline LH (IE/l) & $12.4 \pm 7.3(1.0,44.0)$ & $9.3 \pm 5.7(1.6,29.6)^{* *}$ & $11.3 \pm 6.1(1.2,27.9)$ & $9.1 \pm 6.2(1.3,24.3)$ \\
\hline HbA1c (\%) & $5.4 \pm 0.3(4.8,5.9)$ & $5.4 \pm 0.3(5,6.3)$ & $5.2 \pm 0.5(4.4,6.6)$ & $5.2 \pm 0.6(4,6)$ \\
\hline Fasting blood glucose $(\mathrm{mmol} / \mathrm{l})$ & $5.2 \pm 0.6(4.0,6.1) \S \S$ & $5.2 \pm 0.5(4.4,6.6)$ & $4.6 \pm 0.6(4,5.5)$ & $5.0 \pm 0.7(4,6)$ \\
\hline
\end{tabular}

Table 1: Paraclinical data before and after metformin treatment in 117 women (mean \pm SD (range)).

We found after 3-6 months of treatment a significant drop in $\mathrm{LH}$, total testosterone levels and more so in its relative level of bioavailability, the free androgen index, FAI. The non-responding women showed similar trends. The paraclinical values were similarly available in the non-responding women and differed only slightly (Table 1). The results showed no difference in any of the paraclinical results in repect to GDM or diabetes in the family history. Fifty-three of the 117 women had a BMI $\geq 30 \mathrm{~kg} / \mathrm{m}^{2}$ at first visit. In all, $86(74 \%)$ had a clinical check-up 3- 6 months after the initial visit.
Before vs. after treatment: ${ }^{*}: \mathrm{p}<0.05,{ }^{*}: \mathrm{p}<0.01$. Paired, nonparametric and t-test when appropriate, Difference between included and non-responding women: $₫ \mathrm{p}<0.05, \S \S$. $\mathrm{p}<0.01$

The follow-up by questionnaire in the 76 responding women was performed $5 \pm 2$ years after the first visit at which time the women's weight and BMI had significantly decreased ( $88 \pm 21$ to $85 \pm 20 \mathrm{~kg}$ and $31 \pm 7$ to $30 \pm 7 \mathrm{~kg} / \mathrm{m}^{2}, \mathrm{p}<0.02$, paired, non-parametric test). Twentythree percent had managed to decrease their $\mathrm{BMI}<30 \mathrm{~kg} / \mathrm{m}^{2}$. 
Citation: Viftrup-Lund M, Gade M, Lauszus FF (2014) Pregnancy in PCOS Women and their History of Diabetes. J Metabolic Synd 3: 163. doi:

Page 3 of 5

\section{Pregnancies}

At first visit, 47 women were nulligravidae and 29 women had 50 various previous pregnancy outcomes. These historic pregnancies consisted of 26 live births, 17 spontaneous abortion, 6 induced abortions, and one extrauterine pregnancy. Further, in the index pregnancy the women were treated with metformin only, ovarian stimulation, IUI, and IVF in $22,38,8$, and 8 of the cases, respectively. This resulted in 66 live deliveries (eight twins and 58 singletons), nine abortions and one legal abortion. The clinical results of the singleton pregnancies are shown in Table 2.

\begin{tabular}{|c|c|c|c|c|c|}
\hline & GDM in history & No GDM in history & All & $\begin{array}{l}\text { No GDM or family } \\
\text { history of DM }\end{array}$ & $\begin{array}{l}\text { Family history of } \\
\text { DM/GDM }\end{array}$ \\
\hline No. & 14 & 62 & $76 \S$ & 34 & 42 \\
\hline Nulligravidae & 8 & 39 & 47 & 23 & 24 \\
\hline Metformin only & 2 & 20 & 22 & 10 & 12 \\
\hline Ovulation induction & 8 & 30 & 38 & 18 & 20 \\
\hline IUI & 2 & 6 & 8 & 4 & 4 \\
\hline IVF & 2 & 6 & 8 & 2 & 6 \\
\hline Preeclampsia & 2 & 2 & 4 & 2 & 2 \\
\hline Family history of diabetes & 8 & 28 & 42 & 0 & 42 \\
\hline $\begin{array}{l}\text { Spontaneous abortions previously/in index } \\
\text { pregnancy }\end{array}$ & $3 / 2$ & $8 / 7$ & $11 / 9$ & $4 / 3$ & $7 / 6$ \\
\hline Twins & 0 & 8 & 8 & 6 & 2 \\
\hline Hypothyroidism pregravid & - & 2 & 2 & - & 2 \\
\hline Hypertension at follow up & 1 & 3 & 4 & 3 & 1 \\
\hline Singleton birth weight $(n=58)(g) \#$ & $3658 \pm 478$ & $3569 \pm 612$ & $3571 \pm 592$ & $3714 \pm 655$ & $3488 \pm 517$ \\
\hline Singleton length $(\mathrm{cm}) \#$ & $52 \pm 2$ & $52 \pm 2$ & $52 \pm 2.3$ & $53 \pm 3^{*}$ & $52 \pm 2$ \\
\hline Singleton ponderal index (g/dm3)\# & $27 \pm 4$ & $25 \pm 3$ & $25.2 \pm 2.8$ & $25 \pm 2$ & $25 \pm 3$ \\
\hline GDM in history & 14 & - & 14 & 8 & 6 \\
\hline
\end{tabular}

Table 2: The clinical data by history of GDM in 76 responding of PCOS women, $₫$ one woman had a legal, induced abortion, \#: Excluding eight twins, nine abortions, and one extra-uterine pregnancy, ${ }^{*}$ : $\mathrm{p}<0.03$ Mann-Whitney U-test: PCOS women with DM history vs. no DM or GDM in history

In 11 of 66 deliveries GDM was diagnosed in the responding group of PCOS women and further two of 29 deliveries in the nonresponding group. Three of the women who had abortions had gestational diabetes in either the previous or subsequent pregnancy; thus, at follow-up $14 \%$ of the study group had had GDM at some stage. The clinical and obstetrical outcome of the women showed no association with family history of diabetes or GDM (Tables 2 and 3).
Five women had preeclampsia; one of these women had prepregnancy hypertension. Two women had concomitantly hypothyroidism and one woman hypertension; both conditions were diagnosed and treated before pregnancy. No neonatal anthropometric feature was different with respect to family history of diabetes or GDM and no fetal malformations were found; neither in hospital charts nor in the questionnaire.

\begin{tabular}{|c|c|c|c|c|c|}
\hline & Spontaneous abortion & Singleton delivery & Twin deliveries & Induced abortion & Extra-uterine pregnancy \\
\hline No. & 20 & 85 & $10^{* *}$ & 1 & 1 \\
\hline Nulligravidae & 8 & 50 & 6 & 0 & 1 \\
\hline Metformin only & 11 & 27 & 0 & & 0 \\
\hline Ovulation induction & 4 & 36 & 7 & 1 & 1 \\
\hline IUI & 4 & 12 & 3 & & 0 \\
\hline IVF & 1 & 10 & 0 & & 0 \\
\hline
\end{tabular}


Page 4 of 5

\begin{tabular}{|l|l|l|l|l|l|}
\hline Preeclampsia & - & 3 & 1 & & \\
\hline Family history of diabetes & 6 & 28 & 2 & 0 & 0 \\
\hline GDM* $^{*}$ & 2 & 11 & 0 & 1 & 0 \\
\hline Hypothyroidism pregravid & - & 2 & 1 & & \\
\hline Hypertension at follow up & 2 & 1 & 1 & \\
\hline
\end{tabular}

Table 3: Fertility treatment and maternal morbidity by pregnancy outcome in all 117 women, ${ }^{\star}: 2$ women with spontaneous abortions had subsequently a pregnancy with gestational diabetes; the woman with induced abortion had previously had gestational diabetes, ${ }^{\star *}$ : one triplet pregnancy

\section{Discussion}

We find no association of clinical outcome with history of diabetes and GDM despite the pregravid improvement of androgen status by metformin treatment. In this study metformin is only administered preconceptional and during early pregnancy. In contrast, Glueck et el. found decreased early pregnancy loss and gestational weight gain, less GDM and decreased androgen indices in pregnancy with a study design of prospective intervention and retrospective pregnancy loss data $[4,5]$.

A Cochrane review on this subject concludes that concomitant metformin treatment improves clinical pregnancy rates when given in the time before and the immediate beginning of pregnancy with and without fertility treatment [6]. The credit for beneficial effect is given to the improvement of insulin sensitivity markers, which is expressed in general lower blood glucose, $\mathrm{LH}$, and testosterone and an increase of SHBG [7-10]. Our women improve in similar insulin resistance markers.

The obvious bias of our study is that women are treated with different ovarian stimulation regimens, which will improve success rates given that each of the regimens increases the pregnancy rate. On the other hand, if insulin resistance affects pregnancy outcome in PCOS negatively, the dose of metformin would be decisive and not the ovarian stimulation. This was indicated by Khattab et al. who discontinued metformin after conception in a control group of PCOS women [11]. The PCOS women who continued with metformin throughout reduced their incidence of GDM to an OR of 0.17 compared to the control group. Similar the women are highly motivated and may seek a healthier lifestyle, which could include unreported smoking cessation, diet, and weight reduction, all of which also improves insulin resistance.

Metformin intake throughout pregnancy has no androgen lowering effect and, if hyperandrogenism increase risk of GDM, metformin will not likely decrease the risk by this mechanism $[2,3]$. The reported incidence of GDM is variable in PCOS and potential prophylaxis with metformin is, thus, questionable. Glintborg et al. show no effect of metformin in increased inflammatory markers associated with diabetes and metabolic syndrome in PCOS women [12]. Although we screened for hyperglycemia in the pre-pregnancy period we found higher rate of GDM than in the background population. This may be due to the biochemical inclusion criteria together with other potential bias like obesity, age, and diabetes family history. If diabetogenic factors were involved in the etiology of miscarriages and pregnancy outcome of PCOS women, we find the family history or the likeliness of GDM itself seem not to herald increased risk. Thus, the glucose and
HbAlc values at first visit were similar with respect to subsequent GDM and diabetes history. Randomized studies of treatment effects of metformin in early pregnancy showed that obese PCOS have more benefit of treatment; this is suggestive for environmental factors' causative effect, i.e. body weight as well as the pregnancy's insulin resistant milieu [10].

To be included in our study group only the first two of the consensus criteria had to be fulfilled, namely oligo- and or an ovulation and clinical and/or biochemical signs of hyperandrogenism, excluding women diagnosed due to polycystic ovaries only [1]. Thus, our inclusion criteria were stricter and perhaps only included the most severe case of PCOS. Similarly, women with ovaries of polycystic morphology (PCO), without any other features of PCOS, show no effect of metformin treatment in a randomized study [13]. We, therefore, recommend the careful selection of study population, as it should limit some of the clinical heterogeneity of PCOS regarding disease phenotype like the ultrasound appearance of ovaries, obesity, hyperandrogenemia, and glycemia.

The varying association of PCOS with GDM depends on the population studied due to genetic factors where the metabolic syndrome in parents and their siblings seems to be fundamental to the pathogenesis of PCOS $[14,15]$. Franks et al. conclude that PCOS is inherited on an oligogenic basis and the co-morbidity and phenotype are due to the interaction of a small number of key genes with environmental and nutritional factors [16].

Selection bias of those who participated in the questionnaire part of the study is not likely as the non-responding women had comparable $\mathrm{BMI}$, testosterone, and $\mathrm{HbAlc}$ as to the responding women. Nearly half of women $(45 \%)$ in our study are obese and $47 \%$ had a family history of diabetes mellitus. Further, our incidence of GDM in $14 \%$ of the women seems reasonable compared with other studies in similar populations $[2,3,15]$.

We have no reason to believe that the women were disfavored by commencing on metformin. On the contrary, we even find that the women lost weight since the initial visit five years previously which suggests that the women are motivated and have focus on the weight issue after pregnancy. Whether metformin has any long-term effect on diabetes prevention, weight reduction, and hyperandrogenism in PCOS remains unsolved.

To date only sparse data are available regarding the effect of metformin on a large scale when administered throughout the pregnancy [17]. Vanky et al. show in their randomized study that metformin administered from third month and throughout pregnancy 
Citation: Viftrup-Lund M, Gade M, Lauszus FF (2014) Pregnancy in PCOS Women and their History of Diabetes. J Metabolic Synd 3: 163. doi: 10.4172/2167-0943.1000163

Page 5 of 5

is not associated with any improved outcome in terms of neonatal and maternal complications, i.e. GDM; preeclampsia, preterm delivery [3].

In conclusion, GDM and family history of diabetes is not associated with unfavorable pregnancy outcome in PCOS women.

\section{References}

1. Rotterdam ESHRE/ASRM-Sponsored PCOS Consensus Workshop Group (2004) Revised 2003 consensus on diagnostic criteria and longterm health risks related to polycystic ovary syndrome (PCOS). Hum Reprod 19: 19-25.

2. Vanky E, Carlsen SM (2012) Androgens and antimüllerian hormone in mothers with polycystic ovary syndrome and their newborns. Fertil Steril 97: 509-515.

3. Vanky E, Stridsklev S, Heimstad R, Romundstad P, Skogøy K, et al. (2010) Metformin versus placebo from first trimester to delivery in polycystic ovary syndrome: a randomized, controlled multicenter study. J Clin Endocrinol Metab 95: E448-455.

4. Glueck CJ, Wang P, Goldenberg N, Sieve-Smith L (2002) Pregnancy outcomes among women with polycystic ovary syndrome treated with metformin. Hum Reprod 17: 2858-2864.

5. Glueck CJ, Bornovali S, Pranikoff J, Goldenberg N, Dharashivkar S, et al (2004) Metformin, pre-eclampsia, and pregnancy outcomes in women with polycystic ovary syndrome. Diabet Med 21: 829-836.

6. Tang T, Lord JM, Norman RJ, Yasmin E, Balen AH (2010) Insulinsensitising drugs (metformin, rosiglitazone, pioglitazone, D-chiroinositol) for women with polycystic ovary syndrome, oligo amenorrhoea and subfertility. Cochrane Database Syst Rev CD003053.

7. Jakubowicz DJ, Iuorno MJ, Jakubowicz S, Roberts KA, Nestler JE (2002) Effects of metformin on early pregnancy loss in the polycystic ovary syndrome. J Clin Endocrinol Metab 87: 524-529.

8. Palomba S, Falbo A, Orio F Jr, Zullo F (2009) Effect of preconceptional metformin on abortion risk in polycystic ovary syndrome: a systematic review and meta-analysis of randomized controlled trials. Fertil Steril 92: 1646-1658.
9. Boomsma CM, Eijkemans MJ, Hughes EG, Visser GH, Fauser BC, et al. (2006) A meta-analysis of pregnancy outcomes in women with polycystic ovary syndrome. Hum Reprod Update 12: 673-683.

10. Morin-Papunen L, Rantala AS, Unkila-Kallio L, Tiitinen A, Hippeläinen M, et al. (2012) Metformin improves pregnancy and live-birth rates in women with polycystic ovary syndrome (PCOS): a multicenter, doubleblind, placebo-controlled randomized trial. J Clin Endocrinol Metab 97: 1492-1500.

11. Khattab S, Mohsen IA, Aboul Foutouh I, Ashmawi HS, Mohsen MN, et al. (2011) Can metformin reduce the incidence of gestational diabetes mellitus in pregnant women with polycystic ovary syndrome? Prospective cohort study. Gynecol Endocrinol 27: 789-793.

12. Glintborg D, Mumm H, Altinok ML, Richelsen B, Bruun JM, et al. (2014) Adiponectin, interleukin-6, monocyte chemoattractant protein-, and regional fat mass during 12-month randomized treatment with metformin and/or oral contraceptives in polycystic ovary syndrome. J Endocrinol Invest (In press).

13. Swanton A, Lighten A, Granne I, McVeigh E, Lavery S, et al. (2011) Do women with ovaries of polycystic morphology without any other features of PCOS benefit from short-term metformin co-treatment during IVF? A double-blind, placebo-controlled, randomized trial. Hum Reprod 26: 2178-2184.

14. Leibel NI, Baumann EE, Kocherginsky M, Rosenfield RL (2006) Relationship of adolescent polycystic ovary syndrome to parental metabolic syndrome. J Clin Endocrinol Metab 91: 1275-1283.

15. Helseth R, Vanky E, Salvesen O, Carlsen SM (2013) Gestational diabetes mellitus among Norwegian women with polycystic ovary syndrome: prevalence and risk factors according to the WHO and the modified IADPSG criteria. Eur J Endocrinol 169: 65-72.

16. Franks S, Gharani N, Waterworth D, Batty S, White D, et al. (1997) The genetic basis of polycystic ovary syndrome. Hum Reprod 12: 2641-2648.

17. Ekpebegh CO, Coetzee EJ, van der Merwe L, Levitt NS (2007) A 10-year retrospective analysis of pregnancy outcome in pregestational Type 2 diabetes: comparison of insulin and oral glucose-lowering agents. Diabet Med 24: 253-258. 